\title{
Acute Intermittent Porphyria in Prepubertal Child-diagnostic and Therapeutic Challenges in India: A Case Report and Literature Review
}

\author{
Ankita Goel Sharma ${ }^{1} \odot$, Kaveri Pandit ${ }^{\circledR} \odot$, Shalu Gupta ${ }^{3} \odot$, Virendra Kumar ${ }^{4} \odot$
}

\begin{abstract}
Acute intermittent porphyria (AIP) is autosomal dominant metabolic disorder of adulthood with limited case reports in children. Literature review from Western countries shows that most children present with non-specific gastrointestinal and neuropsychiatric symptoms with no family history. Moreover, the attacks are recurrent and precipitated by various factors (drugs/infection). We describe the case of 11 -year-old male child who presented with acute abdominal pain, seizures, hypertension, quadriparesis, neuropathy, and respiratory weakness necessitating ventilatory and intensive care. Diagnosis of AIP was suspected on basis of bedside urine testing and confirmed with hydroxymethylbilane synthase gene mutation study. Besides supportive therapy, child was managed successfully with intravenous hemin, an orphan drug, which was procured with great difficulty. This case is presented for highlighting the diagnostic and therapeutic challenges faced in management of such cases in a developing country. We also review Indian literature for similar cases and discuss the clinical presentation, diagnosis, and management of AIP in children.

Keywords: Acute intermittent porphyria, Hemin, Hydroxymethyl bilane synthase gene mutation, Pediatric intensive care unit, Prepubertal child. Indian Journal of Critical Care Medicine (2022): 10.5005/jp-journals-10071-24133
\end{abstract}

\section{INTRODUCTION}

Acute intermittent porphyria (AIP), resulting from decreased activity of enzyme porphobilinogen deaminase, is characterized by classical triad of abdominal pain, neurologic dysfunction, and behavioral changes. The vague nonspecific symptoms, multisystem involvement, variability in clinical vignettes, absent family history, low childhood prevalence, and unfamiliarity with diagnostic and therapeutic aspects among pediatricians often cause delay in diagnosis and management of such children, despite a wellcharacterized molecular genetics. ${ }^{1}$ We here report a prepubertal boy with clinical features suggestive of AIP, managed successfully with injection hemin. We also systematically review the Indian literature for similar cases.

\section{Case Description}

A 11-year-old male child, presented with projectile vomiting and epigastric pain for 10 days and multiple seizure episodes for 7 days, managed conservatively with antiepileptics (phenytoin and leveraticetam). After 5 days of admission outside, he developed weakness of all four limbs, left-sided facial deviation and abnormal behavior over next three days. This was followed by onset of breathing difficulty, fever, and burning micturition for one day for which he was referred to our emergency. There was no history of tuberculosis contact or any similar complaints in family. On admission, child was conscious, oriented, anxious with mild respiratory distress, and high blood pressure (147/107 mm Hg). Neurological examination revealed quadriparesis (proximal power $2 / 5$ and distal power $3 / 5$ in both upper and lower limbs), hypotonia, absent reflexes, and upgoing plantars. Cranial nerve examination was suggestive of right upper motor neuron facial palsy. Rest systemic examination was essentially normal. Investigations done revealed metabolic alkalosis, hyponatremia (118 meq/dL),

\footnotetext{
${ }^{1-4}$ Department of Pediatrics, Lady Hardinge Medical College and Kalawati Saran Children Hospital, New Delhi, India

Corresponding Author: Ankita Goel Sharma, Department of Pediatrics, Lady Hardinge Medical College and Kalawati Saran Children Hospital, New Delhi, India, Phone: +919711278490, e-mail: ankitagoel.85@ gmail.com

How to cite this article: Sharma AG, Pandit K, Gupta S, Kumar V. Acute Intermittent Porphyria in Prepubertal Child-diagnostic and Therapeutic Challenges in India: A Case Report and Literature Review. Indian J Crit Care Med 2022;26(3):390-394.

Source of support: Nil

Conflict of interest: None
}

hypokalemia (2.7 meq/dL), and transamnitis (SGOT/SGPT-118/169 IU/L). Child was shifted to PICU and hypertension was managed with antihypertensive drugs (amlodepin and labetalol). Respiratory distress worsened on day 2 with evidence of diaphragmatic weakness in the form of paradoxical respiration and child was put on invasive mechanical ventilation. Investigation panel including sputum CBNAAT for tuberculosis, antinuclear antigen, lumbar puncture, whole abdomen ultrasound, renal Doppler, ECHO, magnetic resonance imaging of brain was within normal limits. It was observed that color of urine turned black on storage for 3-4 hours (Fig. 1A). A strong clinical suspicion of AIP was kept and urine for porphobilinogen by Schwartz test was sent which came positive. Child was started on high-dose dextrose therapy and low-dose benzodiazepines for anxiety and insomnia. Drugs (phenytoin) were modified to avoid further precipitation of attack. Nerve conduction study revealed motor axonal neuropathy. Genetic analysis for exome sequencing was sent for hydroxymethylbilane synthase (HMBS) gene analysis. Child was planned for injection 
hemin administration in view of life-threatening attack. Hemin is an orphan drug manufactured in Europe (heme arginate) and the United States (hematin). Procuring hemin in India was an immensely difficult task due to high drug cost (approx INR 2 lakh for four vials, $250 \mathrm{mg}$ each) and extensive legal documentation and permission required from the Customs and Central Drugs Standard Control Organization of India. The drug (brand name Injection Normosang) was procured with help of Indian Pharmaceutical company and arrived after almost 2 weeks of paperwork and money transfer. Child received hemin (dose 3-5 mg/kg/day for 4 days) and was monitored for side effects. After 6 days of starting hemin, there was improvement in respiratory muscle power, urine color (Fig. 1B), and biochemical parameters. On Day 35 of PICU admission, child was gradually weaned of ventilator and successfully extubated (previous extubation failure prior to hemin). Genetic testing revealed heterozygous mutation c.331 G>A (p.Gly111Arg) in HMBS gene confirming the diagnosis of AIP. No other family member was affected. Quadriparesis remained static; however, psychiatric manifestations and hypertension improved and child was discharged on day 50. On 2-week follow-up, child showed improvement in motor weakness (power $-4 / 5$ at each joint with elicitable reflexes) and respiratory weakness was completely resolved. Child had a repeat milder attack in the form of abdominal pain and altered urine color after 4 months which was again treated with hemin. At present, the child is ambulatory with no new symptoms and is doing well.

\section{Discussion}

Heterozygous AIP is typically a disease of adult females with rare incidence in prepubertal children. By searching Pubmed and Medline, the available literature on Indian children with AIP was collated and summarized in Table 1. In contrast to adults, the majority of children below 14 years were males including our case. Most presented with abdominal (pain, vomiting), neurological (seizures, altered sensorium, motor weakness, nerve palsies), and psychological symptoms (anxiety attack, aggression). In addition, hypertension and hyponatremia were almost universally present similar to our case. These symptoms were associated with fever or use of drugs like chloroquine or antiepileptics (phenytoin-in present case), which maybe important precipitating factors in this age-group. These clinical findings are similar to published literature review on childhood AIP from Western countries. ${ }^{2,3}$

The diagnosis in majority of cases was based on clinical features and urine porphobilinogen detection by Watson Schwartz test or quantitative estimation. The diagnosis of AIP often gets missed due to rarity of disease and unavailability of testing facility at majority of places. Change in urine color on standing provides bedside test for screening in suspected patients. The definite confirmation is by genetic testing for HMBS gene mutation; however, it is expensive and rarely done. Of the total 16 cases in this review, only 3 had HMBS gene mutation analysis done including the patient reported in the present study (c.331 G>A (p.Gly111Arg)). Over 400 types of HMBS gene mutations are known worldwide including missense (majority), nonsense, and splice mutation. The c.331 G>A (p.Gly111Arg) mutation on exon 7 is a known variant of probably damaging pathogenicity leading to protein with approximately $4 \%$ residual HMBS activity, and has been widely implicated in cases worldwide. ${ }^{4}$

Therapeutic options involve definitive therapy in the form of hemin and supportive therapy like high carbohydrate loading (300-500 g/day), symptomatic management, and removal of precipitating factors. Intravenous dextrose in high doses blocks enzyme induction and prevents accumulation of precursors. In severe life-threatening cases, hemin therapy is indicated at 3-5 $\mathrm{mg} / \mathrm{kg} /$ day for $3-5$ days which acts by reducing the ALA synthetase enzyme. Only two cases in the review (including the present case) received hemin injection, while the rest were managed conservatively. The timely import and availability of this orphan drug is a big challenge especially in resource-limited settings like ours. The second important consideration is drug cost and affordability as majority patients belong to lower socioeconomic status. These patients may need hemin to prevent attacks for lifetime and thus need financial and multidisciplinary support for management of disease.

\section{Conclusion}

This report emphasizes the importance of early diagnosis of AIP, intensive care management, and treatment of life-threatening events as well as the challenges faced by us in procuring an orphan drug and its feasibility.
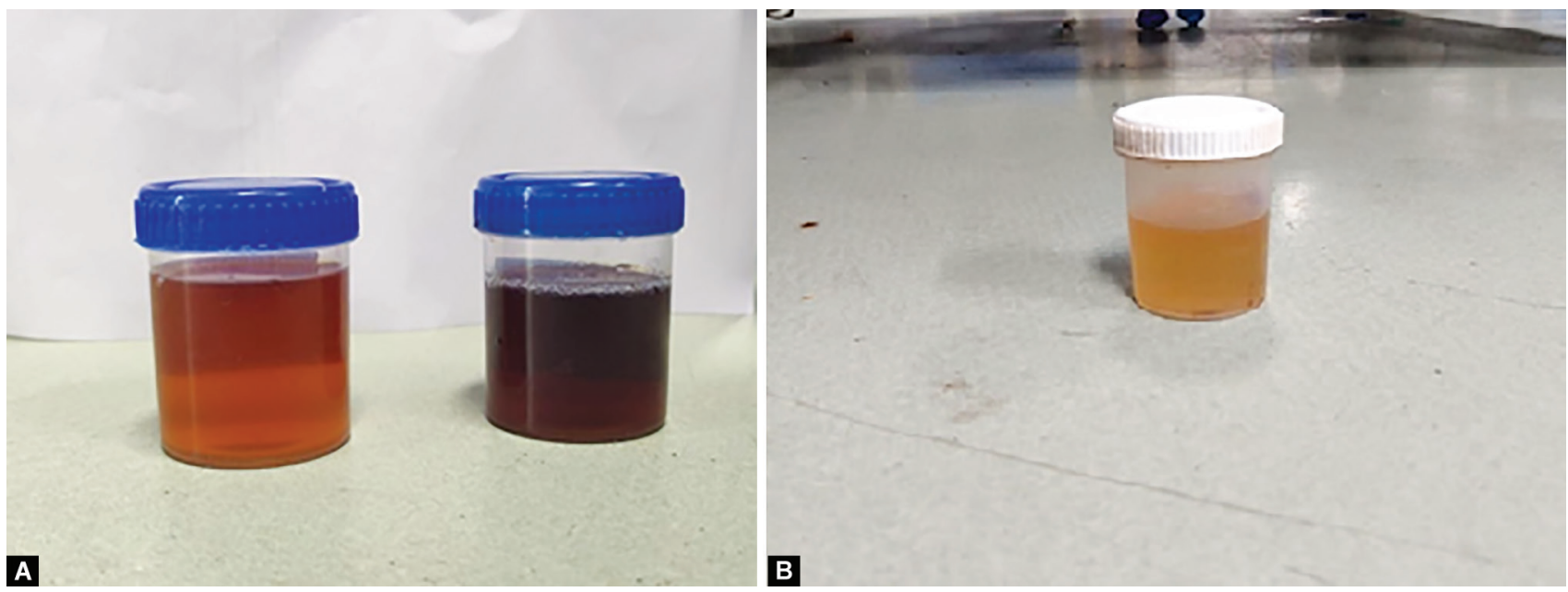

Figs $1 \mathrm{~A}$ and B: (A) Darkening of urine color on storage (on admission to ICU); (B) No change in urine color after administration of hemin 


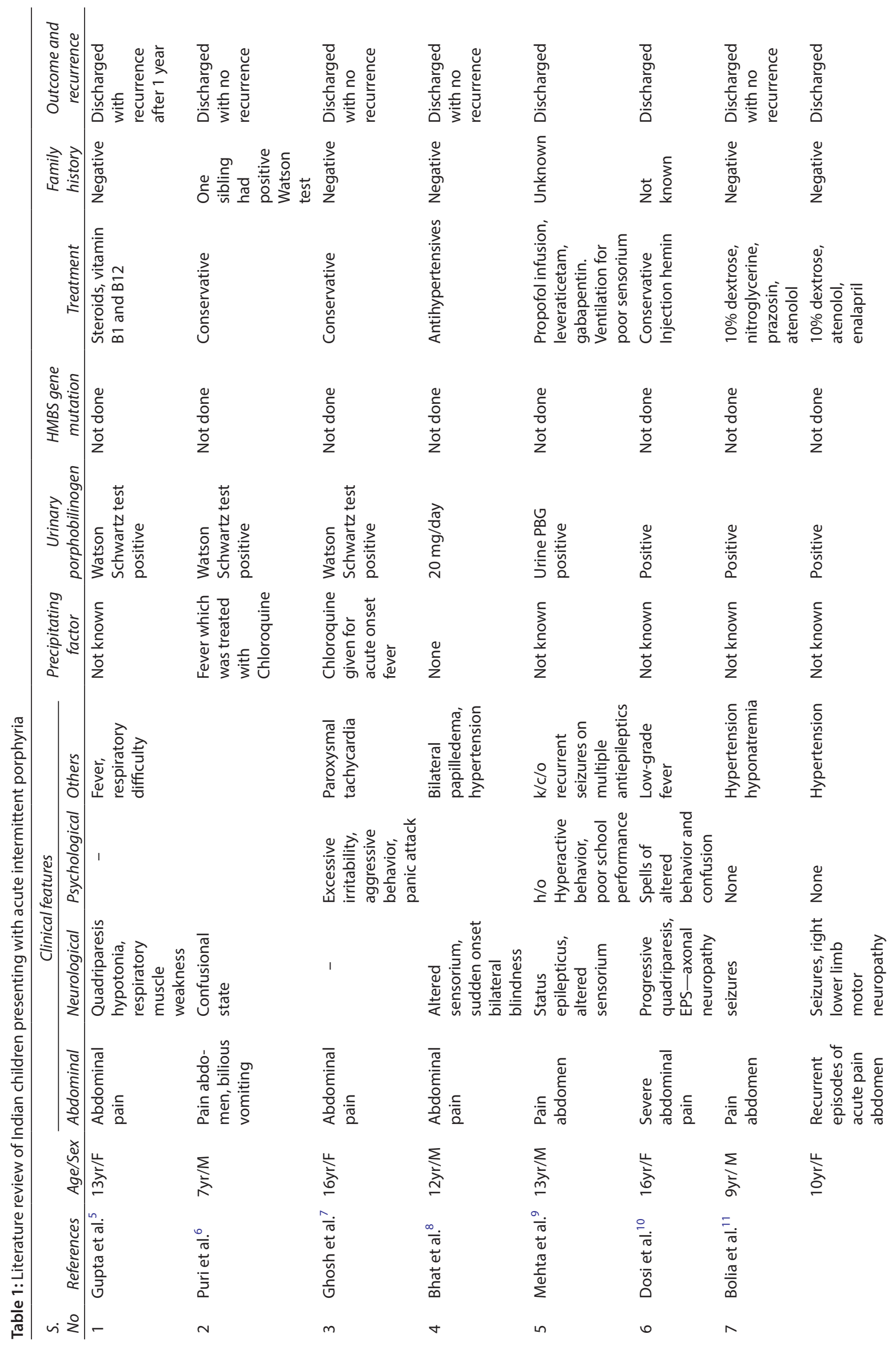




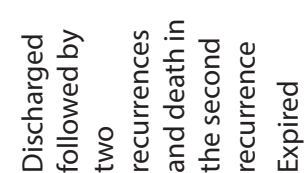

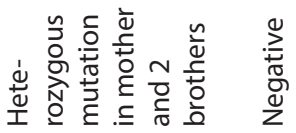

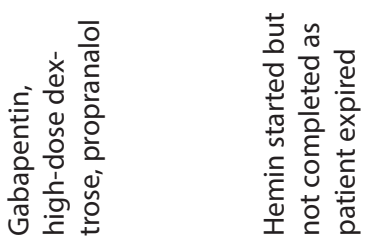

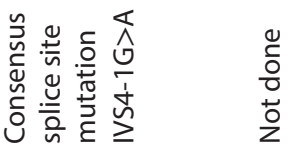

$\stackrel{1}{\circ}$
$\frac{1}{2}$
กิ

ষ্ড

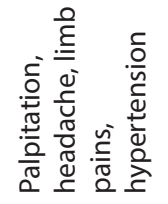

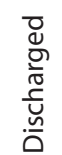

$\underset{\substack{0 \\ \frac{\pi}{2}}}{2}$

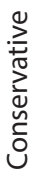

$\stackrel{0}{0}$
$\frac{0}{0}$
$\stackrel{0}{0}$

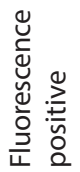

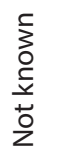

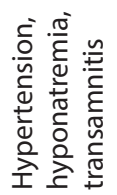

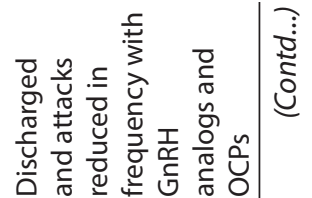

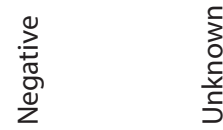

$\stackrel{0}{ \pm}$
$\stackrel{0}{0}$
$\stackrel{0}{0}$
$\stackrel{0}{0}$
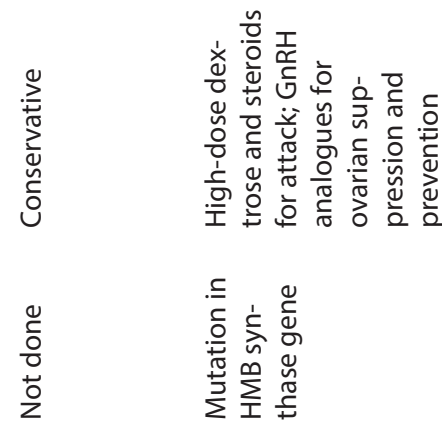

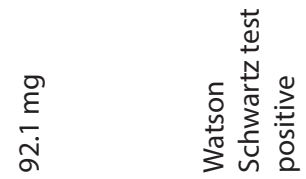
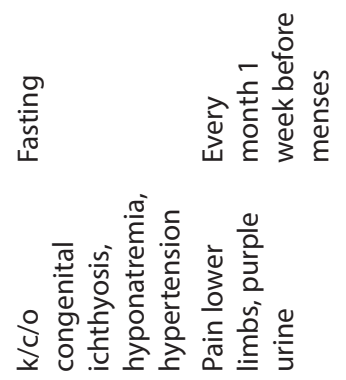

$\overline{\bar{z}}$

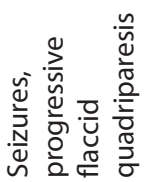

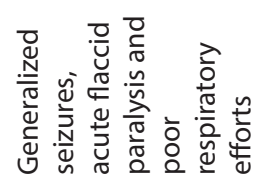

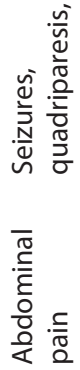

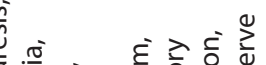

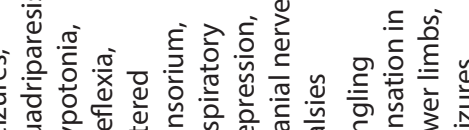

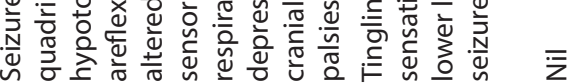

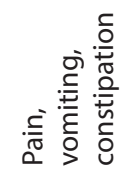

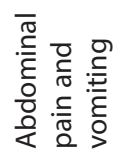

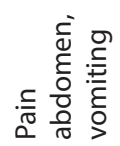

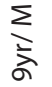

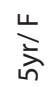

$\underset{\Sigma}{\Sigma}$

$\sum_{\text {à }}^{\stackrel{u}{\Delta}}$

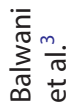

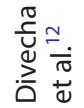

$\infty$

a

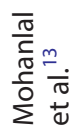

$ㅇ$

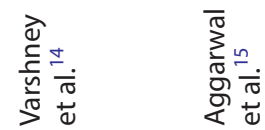

$=\quad \simeq$ 


\section{OrCID}

Ankita Goel Sharma (1) https://orcid.org/0000-0003-0971-6032

Kaveri Pandit (1) https://orcid.org/0000-0001-8578-5633

Shalu Gupta @ https://orcid.org/0000-0003-0494-0465

Virendra Kumar (1) https://orcid.org/0000-0001-6752-9281

\section{REFERENCES}

1. Herrick AL, McColl K. Acute Intermittent Porphyria. Best Pract Res Clin Gastroenterol 2005;19(2):235-249. DOI: 10.1016/j.bpg.2004.10.006.

2. Kaplan PW, Lewis DV. Juvenile Acute Intermittent Porphyria with Hypercholesterolemia and Epilepsy: A Case Report and Review of the Literature. J Child Neurol 1986;1:38-45. DOI: 10.1177/088307388600100106.

3. Balwani $M$, Singh $P$, Seth $A$, et al. Acute Intermittent Porphyria in children: A case Report and Review of the Literature. Mol Genet Metab 2016;119(4):295-299. DOI: 10.1016/j.ymgme.2016.10.005.

4. Lenglet $H$, Schmitt $C$, Grange T, et al. From a Dominant to an Oligogenic Model of Inheritance with Environmental Modifiers in Acute Intermittent Porphyria. Hum Mol Genet 2018;27(7):1164-1173. DOI: $10.1093 / \mathrm{hmg} / \mathrm{ddy} 030$.

5. Gupta HL, Singh H, Prabhaker B R. Acute Intermittent Porphyria in Childhood- Report of a Case and Review of Literature. Indian J Pediatr 1967;34:146-150. Available from: https://doi.org/10.1007/ BF02756413.

6. Puri AS, Rawal KK, Gupta R, Broor SL. Precipitation of Acute Intermittent Porphyria by Chloroquin. Indian Pediatr 1996;33(3): 241-243. PMID: 9255018.

7. Ghosh S, Chaudhury PK, Goswami HK. An Analysis of Six Cases of Acute Intermittent Porphyria. Indian J Psychiatry 2006;48(3):189-192. DOI: 10.4103/0019-5545.31584.

8. Bhat JI, Qureeshi UA, Bhat MA. Acute Intermittent Porphyria with Transient Cortical Blindness. Indian Pediatr 2010;47(11):977-978. DOI: 10.1007/s13312-010-0152-9.

9. Mehta M, Rath GP, Padhy UP, Marda M, Mahajan C, Dash HH. Intensive Care Management of Patients with Acute Intermittent Porphyria: Clinical Report of Four Cases and Review of Literature. Indian J Crit Care Med 2010;14(2):88-91. DOI: 10.4103/0972-5229.68222.

10. Dosi RV, Ambaliya AP, Patell RD, Sonune NN. Challenges in the Diagnosis and Treatment of a Case of Acute Intermittent Porphyria in India. J Postgrad Med 2013;59(3):241-242. DOI: 10.4103/00223859.118056.

11. Bolia R, Srivastava A, Poddar U, Yachha SK. Acute Intermittent Porphyria: A Missed Diagnosis in Pre-Pubertal Children with Recurrent Abdominal Pain. Trop Gastroenterol 2015;36(4):263-266. Available from: http://dx.doi.org/10.7869/tg.302.

12. Divecha C, Tullu MS, Gandhi A, Deshmukh CT. Acute Intermittent Porphyria: A Critical Diagnosis for Favorable Outcome. Indian J Crit Care Med 2016;20(7):428-431. DOI: 10.4103/0972-5229.186262.

13. Mohanlal S, Ghildiyal RG, Kondekar A, Wade P, Sinha R. A Commonly Missed Well Known Entity-Acute Intermittent Porphyria: A Case Report. J Clin Diagn Res 2016;10(10):SD01-SD02. DOI: 10.7860/ JCDR/2016/20464.8609.

14. Varshney GA, Saini PA, Ghure U. A Rare Case of Acute Intermittent Porphyria with Ichthyosis Vulgaris in a Young Boy. J Family Med Prim Care 2018;7:261-263. DOI: 10.4103/jfmpc.jfmpc_141_17.

15. Aggarwal A, Kulshreshtha B. Catamenial Acute Intermittent Porphyria Managed with GnRH Analogues and Estrogen and Progesterone Add-back Therapy. J Pediatr Adolesc Gynecol 2020;33(4):432-434. DOI: 10.1016/j.jpag.2020.02.009.

16. Bhattiprolu RK, Sardana V. Neurological Manifestations of Acute Intermittent Porphyria: Case Series and Current Review. Apollo Med 2020;2:78-83. DOI: 10.4103/am.am_11_20. 